\title{
A model for the synthesis of naturally occurring benzisochromenequinones
}

\author{
Robin G.F. Giles, ${ }^{\mathrm{a}, *}$ Ivan R. Green ${ }^{\mathrm{b}, *}$, and C. Peter Taylor $^{\mathrm{a}}$ \\ ${ }^{a}$ Chemistry Department, Murdoch University, Murdoch, WA 6150, Australia \\ ${ }^{b}$ Chemistry Department, University of the Western Cape, Bellville, 7530, South Africa \\ E-mail: R.Giles@Murdoch.edu.au; igreen@uwc.ac.za
}

This paper is dedicated to Professor Don W. Cameron on the occasion of his retirement

(received 15 Dec 01; accepted 29 Jan 02; published on the web 06 Feb 02)

\begin{abstract}
1,3-Dimethylbenzisochromene-5,10-quinone $\mathbf{1 4}$ is obtained in good yield when 2-(1'hydroxyethyl)-3-prop-2"-enyl-1,4-naphthoquinone $\mathbf{1 3}$ is treated briefly with bisacetonitriledichloropalladium(II) in solution in dichloromethane at room temperature.
\end{abstract}

Keywords: Benzisochromenequinones, naphthoquinone, isacetonitriledichloropalladium

\section{Introduction}

Significant interest continues to be shown in the synthesis of naturally occurring benzisochromanequinones, ${ }^{1}$ compounds which collectively possess a considerable array of biological properties. ${ }^{2}$ The pyran ring of the targets has the potential for three asymmetric centres, and considerable effort has been expended in achieving the desired stereochemistry, both for the racemates ${ }^{3-6}$ and for the enantiopure compounds. ${ }^{7-9}$ Naturally occurring benzisochromenequinones have also been reported, ${ }^{1}$ although their syntheses have hitherto received less attention. Nevertheless, two elegant short assemblies of these compounds from 2(1'-hydroxyethyl)-1,4-naphthoquinone have been reported recently, ${ }^{10,11}$ and the former method extended to the assembly of the related benzisochromanequinones through stereoselective reduction. We have shown previously that 3-allyl-2-(1'-hydroxyethyl)-1,4-dimethoxynaphthalene 1 undergoes a completely diastereoselective base-induced cyclisation to afford solely the isomeric trans 1,3-dimethylnaphthopyran 2 in virtually quantitative yield, ${ }^{12}$ and that the conjugated double bond structural isomer $\mathbf{3}$ of substrate $\mathbf{1}$ undergoes oxidative cyclisation with ceric ammonium nitrate (four equivalents) to yield directly the 7,9-dideoxy analogues $\mathbf{4}$ and $\mathbf{5}^{13}$ of the aphid insect pigment derivatives quinone A 6 and quinone $\mathrm{A}^{\prime} 7{ }^{14}$ Quinone $\mathrm{A}$ and glucoside B 8 are products derived from the reduction of protoaphin- $f b .{ }^{14}$ A by-product of this 
reaction was identified as the benzisochromenequinone, anhydroquinone A $9{ }^{14,15}$<smiles>C=CCc1c(C(C)O)c(OC)c2ccccc2c1OC</smiles>

1
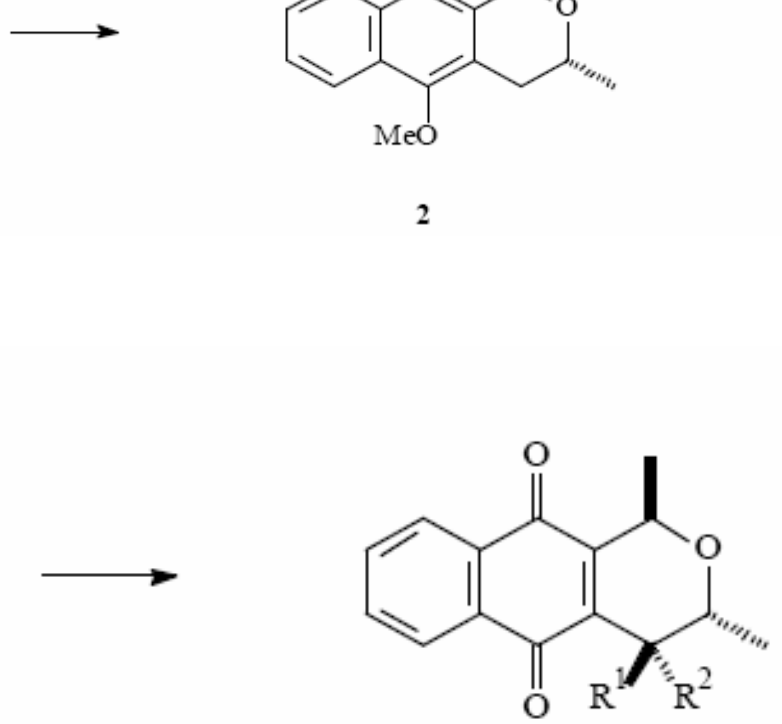

$4 \mathrm{R}^{1}=\mathrm{OH}, \mathrm{R}^{2}=\mathrm{H}$

$5 \mathrm{R}^{1}=\mathrm{H}, \mathrm{R}^{2}=\mathrm{OH}$

\section{Scheme 2}<smiles>[Z]C1([Z])C2=C(C(=O)c3c(O)cc(O)cc3C2=O)[C@@H](C)O[C@@H]1C</smiles>

$6 \mathrm{R}^{1}=\mathrm{OH}, \mathrm{R}^{2}=\mathrm{H}$

$7 \mathrm{R}^{1}=\mathrm{H}, \mathrm{R}^{2}=\mathrm{OH}$<smiles>COc1cccc2c(O)c3c(c(OC)c12)C=C(C)OC3C</smiles>

10<smiles>COc1cc(O)cc2cc3c(c(O)c12)[C@@H](C)O[C@H](C)[C@H]3O</smiles>

8<smiles>CC1=CC2=C(C(=O)c3c(O)cc(O)cc3C2=O)C(C)O1</smiles>

9<smiles>C=CCOc1cc(C(C)=O)c(OC)c2ccccc12</smiles> 
The same compound was obtained by treatment of either quinone A $\mathbf{6}$ or quinone A' $\mathbf{7}$ with acid. ${ }^{15}$ Following our interest in the assembly of derivatives of the aphid insect pigments, we report now ${ }^{16}$ on a ready synthesis of the benzisochromenequinone $\mathbf{1 4}$ as a model for the assembly of anhydroquinone A 9 through a palladium-initiated cyclisation of the 3-allyl-2-(1'hydroxyethyl)-1,4-naphthoquinone 13, the quinonoid analogue of naphthalene $\mathbf{1}$.

\section{Results and Discussion}

There are many examples of nucleophilic addition to a double bond activated by coordination with a palladium(II) complex. ${ }^{17}$ Intramolecular alkoxypalladation/elimination of hydroxyalkenes is also well known. In 1985, Semmelhack et al. reported the formation of the benzisochromene $\mathbf{1 0}$ in a 9\% yield as a by-product in the synthesis of methyl dihydronaphthopyranylacetates using a palladium(II) catalysed olefin carbonylation reaction in methanol. ${ }^{18}$ In the absence of carbon monoxide and methanol, a simple alkenol was cyclised to a mixture of two pyrans, the ratio of which was dependent on the choice of solvent. ${ }^{19}$ We had shown, on the other hand, that catalytic quantities of bisacetonitriledichloropalladium(II) isomerise an $(E) /(Z)$ mixture of an orthohydroxyalkylstyrene into the pure $(E)$-isomer. ${ }^{20}$

Table 1. Cyclisation of naphthalene 1 with bis(acetonitrile)dichloropalladium(II)

\begin{tabular}{|c|c|c|c|c|}
\hline $\begin{array}{c}\text { Amount of } \\
\text { Reagent }\end{array}$ & Reaction Time & $\begin{array}{c}\text { Reaction } \\
\text { Temperature }\end{array}$ & $\begin{array}{c}\text { Yield of Pyran } \\
12\end{array}$ & $\begin{array}{c}\text { Yield of } \\
\text { Compound } 3\end{array}$ \\
\hline 1 m.e. & $10 \mathrm{~min}$ & Reflux & $51 \%$ & - \\
\hline 1 m.e. & $3 \mathrm{~min}$ & Room Temp. & $50 \%$ & - \\
\hline 0.6 m.e. & $13 \mathrm{~min}$ & Room Temp. & $45 \%$ & - \\
\hline 0.55 m.e. & $5 \mathrm{~min}$ & Room Temp. & $51 \%$ & - \\
\hline 0.55 m.e. & $1 \mathrm{~h}$ & 0 oC & $52 \%$ & $7 \%$ \\
\hline 0.3 m.e. & $6 \mathrm{~min}$ & Room Temp. & $47 \%$ & $20 \%$ \\
\hline
\end{tabular}

The known ${ }^{12}$ naphthalene 1 was conveniently prepared here in high overall yield from 2- 
acetyl-4-allyloxy-1-methoxynaphthalene $\mathbf{1 1},{ }^{21}$ which was subjected to a Cope isomerisation and methylation, followed by reduction. ${ }^{12}$ Initially, a solution of naphthalene $\mathbf{1}$ in dichloromethane was treated at room temperature with one equivalent of bis(acetonitrile)dichloropalladium(II). The reaction was completed in three minutes to give a 50\% yield of benzisochromene 12 (Scheme 3).

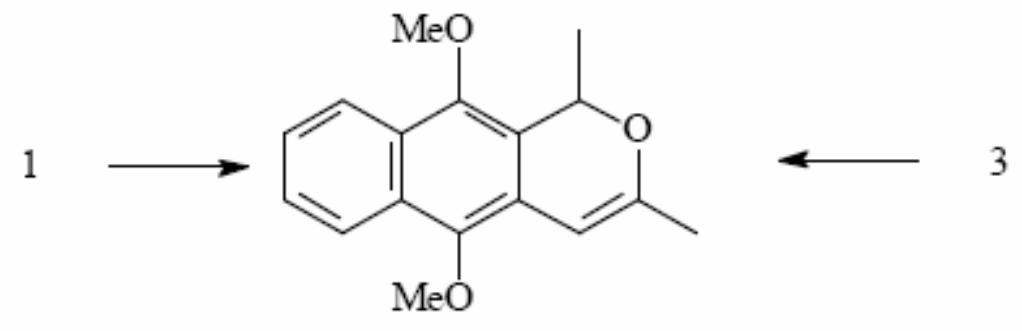

12

\section{Scheme 3}

In this instance, no other material was recovered. Different conditions and amount of reagent did not significantly increase the yield. It was found that when the reaction was performed at $0{ }^{\circ} \mathrm{C}$, or 0.3 equivalents of reagent were used, then conjugated isomer $\mathbf{3}$ of $\mathbf{1}$ was also isolated. This last case, in which significantly less than one equivalent of palladium complex was used, led to the highest recovery of material with little cost to the yield of cyclised product. These results are summarized in Table 1.

It was found that if the conjugated material $\mathbf{3}$ was treated with one equivalent of the same palladium(II) reagent then a $48 \%$ yield of benzisochromene 12 was obtained (Scheme 3 ).

It was not possible, however, to oxidise this benzisochromene 12 to the corresponding 5,10quinone 14 using standard conditions, including silver(II) oxide, ${ }^{22}$ ceric ammonium nitrate ${ }^{23}$ and others. $^{24}$

As an alternative, the possibility of cyclising 3-allyl-2-(1'-hydroxyethyl)-1,4-naphthoquinone 13 was investigated. The naphthalene derivative 1 was oxidised smoothly with ceric ammonium nitrate (two equivalents) to give the quinone $\mathbf{1 3}$ in $\mathbf{8 6 \%}$ yield. This outcome is in sharp contrast to the alternative oxidative cyclisation mentioned above (Scheme 2) which is achieved for the isomeric conjugated propenyl substituent. ${ }^{13}$ The use of ceric ammonium nitrate (four equivalents) gave the same quinone 13, but in reduced yield (72\%), presumably as a consequence of oxidative decomposition of this product.

The quinone $\mathbf{1 3}$ was then treated with bis(acetonitrile)dichloropalladium(II) to form the benzisochromenequinone 14 in reasonable yield (Scheme 4). The best result was found to be a $60 \%$ yield (82\% based on consumed starting material) when 0.15 equivalents of palladium(II) reagent were used at room temperature. Larger amounts of the palladium(II) reagent gave lower yields. These results are summarised in Table 2. It is noteworthy that material not cyclised at the quinonoid level was the non-conjugated starting material 13, whereas non-cyclised material 
recovered from the cyclisation of naphthalene $\mathbf{1}$ is the conjugated isomer $\mathbf{3}$.

1

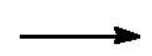<smiles>C=CCC1=C(C(C)O)C(=O)c2ccccc2C1=O</smiles>

13<smiles>CC1=CC2=C(C(=O)c3ccccc3C2=O)C(C)O1</smiles>

14

\section{Scheme 4}

Table 2. Cyclisation of naphthoquinone $\mathbf{1 3}$ with bis(acetonitrile)dichloropalladium(II)

$\begin{array}{cccc}\text { Amount of Reagent } & \begin{array}{l}\text { Reaction Time, } \\ \text { Reaction Temp. }\end{array} & \text { Yield of quinone 14 } & \begin{array}{c}\text { Yield of Starting } \\ \text { Material } \mathbf{1 3}\end{array}\end{array}$

0.55 m.e. $\quad 5$ min, room temp. $\quad 34 \%$

0.30 m.e. $\quad 5 \mathrm{~min}$, room temp. $\quad 39 \%$

0.15 m.e. $\quad 5$ min, room temp. $\quad 60 \% \quad 28 \%$

0.08 m.e. $\quad 5$ min, room temp. $\quad 38 \% \quad 45 \%$

This method therefore has the potential to provide access to naturally occurring benzisochromenequinones. Assembly of the naphthoquinone 13 in monochiral form would provide the correct absolute stereochemistry at $\mathrm{C}-1$ of the benzisochromenequinone, as in anhydroquinone A 9.

\section{Experimental Section}


1,4-Dimethoxy-2-(1'-hydroxyethyl)-3-prop-2"-enylnaphthalene (1). Compound $11^{21}$ (192 mg, $0.74 \mathrm{mmol}$ ) was heated at $160{ }^{\circ} \mathrm{C}$ for $7 \mathrm{~h}$. The unstable residue was identified by ${ }^{1} \mathrm{H}$ NMR spectroscopy as the known 2-acetyl-3-allyl-1-methoxy-4-naphthol. ${ }^{21}$ Without further purification the crude product was then dissolved in dry acetone $(15 \mathrm{~mL})$ containing dimethyl sulphate $(0.285$ g, $2.26 \mathrm{mmol})$. Potassium carbonate $(0.313 \mathrm{~g}, 2.26 \mathrm{mmol})$ was then added and the mixture heated under reflux overnight (13 h). The solution was cooled, filtered and the filtrate concentrated under reduced pressure. The residue was dissolved in diethyl ether and washed with aqueous ammonia solution (28\%) and water. The crude solution was dried over magnesium sulphate and chromatographed (radial, $10 \%$ ethyl acetate-petroleum ether) to give the known ${ }^{12} 2$-acetyl-1,4dimethoxy-3-prop-2\$-enylnaphthalene (186 mg, 92\%), which was reduced according to the literature. $^{12}$

5,10-Dimethoxy-1,3-dimethylbenzisochromene (12). Method A [From compound 1] Bis(acetonitrile)dichloropalladium (II) $(0.111 \mathrm{~g}, 0.43 \mathrm{mmol})$ was added to a solution of compound $1(0.212 \mathrm{~g}, 0.78 \mathrm{mmol})$ in dry dichloromethane $(10 \mathrm{~mL})$ at $0{ }^{\circ} \mathrm{C}$ and the mixture stirred at $0{ }^{\circ} \mathrm{C}$ for $1 \mathrm{~h}$. The mixture was concentrated under reduced pressure and passed through a silica plug (5\% ethyl acetate-petroleum ether). The crude product was then chromatographed (radial, $10 \%$ ethyl acetate-petroleum ether) to give two products: The higher $\mathrm{R}_{\mathrm{f}}$ compound was identified as the title product $12\left(0.110\right.$ g, 52\%) (Found: $\mathrm{C}, 75.2 ; \mathrm{H}, 6.95 . \mathrm{C}_{17} \mathrm{H}_{18} \mathrm{O}_{3}$ requires $\mathrm{C}$, 75.5; H, 6.7\%) (Found: $\mathrm{M}^{+}, 270.1260 . \mathrm{C}_{17} \mathrm{H}_{18} \mathrm{O}_{3}$ requires $\left.\mathrm{M}, 270.1256\right)$; vmax $2928(\mathrm{C}-\mathrm{H}), 1653$ $(\mathrm{C}=\mathrm{C}) ; \delta \mathrm{H} 1.47$ (3H, d, $J$ 6.6, 1- $\mathrm{CH}_{3}$ ), 2.00 (3H, d, $J$ 0.7, 3- $\mathrm{CH}_{3}$ ), 3.89 and 3.95 (each 3H, s, 5$\mathrm{OCH}_{3}$ and 10- $\left.\mathrm{OCH}_{3}\right), 5.75(1 \mathrm{H}, \mathrm{q}, J$ 6.6, 1-H), $5.98(1 \mathrm{H}, \mathrm{q}, J$ 0.7, 4-H), 7.36-7.47 (2H, m, 7-H and 8-H), 7.95-8.04 (2H, m, 6H and 9-H); $\delta \mathrm{C} 20.6\left(1-\mathrm{CH}_{3}\right),{ }^{\mathrm{a}} 20.8\left(3-\mathrm{CH}_{3}\right),{ }^{\mathrm{a}} 61.9\left(5-\mathrm{OCH}_{3}\right),{ }^{\mathrm{b}}$ $62.2\left(10-\mathrm{OCH}_{3}\right),{ }^{\mathrm{b}} 70.0(\mathrm{C} 1), 94.6(\mathrm{C}-4), 119.9(\mathrm{C}-4 \mathrm{a}),{ }^{\mathrm{c}} 122.1(\mathrm{C}-6),{ }^{\mathrm{d}} 122.2(\mathrm{C}-7),{ }^{\mathrm{d}} 123.0(\mathrm{C}-5 \mathrm{a}),{ }^{\mathrm{c}}$ 124.8 (C-8), ${ }^{\mathrm{d}} 126.0$ (C-9), ${ }^{\mathrm{d}} 127.2$ (C-9a), ${ }^{\mathrm{C}} 128.7$ (C-10a), ${ }^{\mathrm{c}} 144.0$ (C-3), ${ }^{\mathrm{e}} 146.5$ (C-5), 152.4 (C10); ${ }^{\mathrm{e}} \mathrm{m} / \mathrm{z} 270$ (M+1 100), 269 (20), 255 (51), 237 (28), 227 (23), 225 (44), 197 (14), 196 (19), 193 (11), 181 (14), 169 (12), 168 (10), 165 (17), 153 (16), 152 (38), 141 (18), 139 (18), 120 (23), 115 (44), 105 (17), 104 (11), 89 (12), 77 (13), 76 (21), 51 (10). The lower $\mathrm{R}_{\mathrm{f}}$ product was identified as the known ${ }^{13}$ trans-2-(1'-hydroxyethyl)-1,4-dimethoxy-3-prop-1"-enylnaphthalene 3 (14 mg, 7\%); $\delta \mathrm{H} 1.63$ (3H, d, $J$ 6.7, 1'- $\mathrm{CH}_{3}$ ), 1.98 (3H, dd, $J 1.7$ and 6.5, 2"- $\mathrm{CH}_{3}$ ), 3.79 and 4.04 (each $3 \mathrm{H}, \mathrm{s}, 1-\mathrm{OCH}_{3}$ and 4-OCH 3$), 5.34(1 \mathrm{H}, \mathrm{dq}, J 6.7$ and 8.2, 1'-H), $6.07(1 \mathrm{H}, \mathrm{dq}, J 6.5$ and 16.0, 2"H), 6.57 (1H, dq, $J 1.7$ and 16.0, 1"-H), 7.46- 7.53 (2H, m, 6-H and 7-H), 7.97-8.04 (1H, m, 5-H or 8-H), 8.07-8.15 (1H, m, 5-H or 8H); $\delta \mathrm{C} 19.2$ (C-2'), $24.7(\mathrm{C}-3 "), 60.8\left(1-\mathrm{OCH}_{3}\right){ }^{\mathrm{a}}, 63.4$ (4$\left.\mathrm{OCH}_{3}\right),{ }^{\mathrm{a}} 67.4\left(\mathrm{C}-1^{\prime}\right), 122.1$ (C1"), ${ }^{\mathrm{b}} 122.8(\mathrm{C}-5),{ }^{\mathrm{b}} 124.0$ (C-6), ${ }^{\mathrm{b}} 125.9$ (C-2), ${ }^{\mathrm{c}} 126.0$ (C-7), ${ }^{\mathrm{b}} 126.1$ (C-8), 127.0 (C-3), ${ }^{\mathrm{C}} 127.6$ (C-4a), ${ }^{\mathrm{c}} 128.4$ (C-8a), ${ }^{\mathrm{c}} 132.8$ (C-2"), 149.9 (C-1), ${ }^{\mathrm{d}} 150.3$ (C-4). ${ }^{\mathrm{d}}$

Method B [From compound 3] Bis(acetonitrile)dichloropalladium (II) (40 mg, $0.154 \mathrm{mmol}$ ) was added to a solution of trans-2-(1'-hydroxyethyl)-1,4-dimethoxy-3-prop-1'-enylnaphthalene 3 (42 $\mathrm{mg}, 0.154 \mathrm{mmol})$ in dry dichloromethane $(7 \mathrm{~mL})$ and the mixture stirred for $11 \mathrm{~min}$. The mixture was concentrated under reduced pressure and chromatographed (5\% ethyl acetate-petroleum ether) to give the title compound 12 (20 mg, 48\%). 
2-(1'-Hydroxyethyl)-3-prop-2''-enyl-1,4-naphthoquinone (13). A solution of cerium(IV) ammonium nitrate $(2.73 \mathrm{~g}, 4.98 \mathrm{mmol})$ in water $(5 \mathrm{~mL})$ was added, over $5 \mathrm{~min}$, to a solution of compound 1 (0.339 g, $1.24 \mathrm{mmol})$ in acetonitrile (40 mL) and water (40 mL). The mixture was then stirred for $1 \mathrm{~h}$. The solution was then poured into water and extracted with dichloromethane. The crude solution was dried (magnesium sulphate), concentrated, and chromatographed (10\% ethyl acetate-petroleum ether) to give the known ${ }^{12}$ 3-(1'-hydroxyethyl)-2-prop-2"-enyl-1,4naphthoquinone 13 as a bright yellow oil $(0.259 \mathrm{~g}, 86 \%) ; \mathrm{H} 1.60\left(3 \mathrm{H}, \mathrm{d}, J\right.$ 6.8, 1'- $\left.\mathrm{CH}_{3}\right), 3.45$ (2H, dt, $J 1.5$ and 6.3, 1"-- $\mathrm{CH}_{2}$ ), 3.91 (1H, d, $J$ 11.0, OH), 4.97 (1H, dq, $J 6.8$ and 11.0, 1'-H), 5.11 (1H, dq, $J 1.5$ and 10.0, vinyl $\left.\mathrm{CH}_{2}\right), 5.14$ (1H, dq, $J 1.5$ and 17.0, vinyl $\left.\mathrm{CH}_{2}\right), 5.84$ (1H, ddt, $J$ 6.3, 10.0 and 17.0, vinyl CH), 7.70-7.76 (2H, m, 6-H and 7-H), 8.04-8.11 (2H, m, 5-H and 8H); $\delta \mathrm{C} 23.6$ (C-2'), 29.8 (C-1"), 67.2 (C-1'), 117.3 (C-3"), 126.2 (C-6), ${ }^{\mathrm{a}} 126.5$ (C-7), ${ }^{\mathrm{a}} 131.6$ (C2), ${ }^{\mathrm{b}} 132.2$ (C-3), 133.5 (C-5), ${ }^{\mathrm{c}} 133.8$ (C-8), ${ }^{\mathrm{c}} 134.0$ (C-2"), ${ }^{\mathrm{c}} 143.3$ (C-4a), ${ }^{\mathrm{d}} 146.4$ (C-8a), ${ }^{\mathrm{d}} 184.4$ (C-1), $187.0(\mathrm{C}-4){ }^{\mathrm{e}}$

1,3-Dimethylbenzisochromene-5,10-quinone (14). Bis(acetonitrile)dichloro-palladium (II) (10 $\mathrm{mg}, 0.038 \mathrm{mmol}$ ) was added to a solution of compound 13 (61 $\mathrm{mg}, 0.252 \mathrm{mmol}$ ) in dry dichloromethane $(8 \mathrm{~mL})$ and the mixture stirred for $5 \mathrm{~min}$. The bright red solution was concentrated under reduced pressure and passed through a silica plug ( $10 \%$ ethyl acetatepetroleum ether). The crude product was then chromatographed (radial, 10\% ethyl acetatepetroleum ether) to give the title compound 14 as a bright red oil (36 mg, 60\%) (Found: C, 74.95; $\mathrm{H}$, 5.1. $\mathrm{C}_{15} \mathrm{H}_{12} \mathrm{O}_{3}$ requires $\mathrm{C}, 75.0 ; \mathrm{H}, 5.0 \%$ ) (Found: $\mathrm{M}^{+}, 240.0777 . \mathrm{C}_{15} \mathrm{H}_{12} \mathrm{O}_{3}$ requires $\mathrm{M}$, 240.0786); vmax $1671(\mathrm{C}=\mathrm{O}), 1652(\mathrm{C}=\mathrm{O}), 1559(\mathrm{C}=\mathrm{C}) ; \delta \mathrm{H} 1.41$ (3H, d, J 6.6, 1- $\left.\mathrm{CH}_{3}\right), 2.03$ (3H, s, 3-CH3), 5.70 (1H, q, J 6.6, 1-H), 5.89 (1H, s, 4-H), 7.64-7.74 (2H, m, 6-H and 9-H), 8.04-8.09 (2H, m, 7-H and 8-H); $\delta \mathrm{C} 18.1$ (1- $\left.\mathrm{CH}_{3}\right), 21.0\left(3-\mathrm{CH}_{3}\right), 69.7$ (C-1), $93.2(\mathrm{C}-4), 125.8$ (C-7), 126.35 (C-8), 126.45 (C-4a), ${ }^{\mathrm{c}} 131.7$ (C-5a), 132.6 (C-9a), ${ }^{\mathrm{c}} 133.0$ (C-6), ${ }^{\mathrm{d}} 133.8$ (C-9), ${ }^{\mathrm{d}}$ 136.2 (C-10a), ${ }^{\mathrm{c}} 162.8$ (C3), 182.0 (C-5), 182.9 (C-10); ${ }^{\mathrm{e}} \mathrm{m} / \mathrm{z} 241$ (M+1, 17), $240\left(\mathrm{M}^{+}, 35\right), 225$ (100), 197 (38), 169 (26), 155 (14), 141 (53), 139 (47), 126 (13), 116 (12), 115 (81), 105 (51), 104 (22), 91 (14), 89 (21), 87 (12), 77 (34), 76 (75), 74 (21), 65 (28), 63 (35), 51 (25), 50 (38). Further elution afforded starting material 13 (17 mg). 


\section{Acknowledgements}

Financial support from the Senate of Murdoch University and the Council of The University of the Western Cape, and an Australian Postgraduate Award (to C.P.T), are gratefully acknowledged.

\section{References}

1. (a) Thomson, R. H. In Naturally Occurring Quinones, 2nd Edition, Academic Press: London, 1971. (b) Thomson, R. H. In Naturally Occurring Quinones III, Recent Advances, 3rd Edition, Chapman and Hall: London, 1987. (c) Thomson, R. H. In Naturally Occurring Quinones IV, Recent Advances, 4th Edition, Chapman and Hall: London, 1997.

2. Brimble, M. A.; Duncalf, L. J.; Nairn, M. R. Nat. Prod. Rep. 1999, 16, 267.

3. Kraus, G. A.; Roth, B. J. Org. Chem. 1978, 43, 4923.

4. Brimble, M. A.; Nairn, M. R. J. Chem. Soc., Perkin Trans. 1 1992, 579.

5. Nomura, K.; Okazaki, K.; Hori, K.; Yoshii, E. J. Am. Chem. Soc. 1987, 109, 3402.

6. Elsworth, J. F.; Giles, R. G. F.; Green, I. R.; Ramdohr, J. E.; and Yorke, S. C. J. Chem. Soc., Perkin Trans. 1 1988, 2469.

7. Okazaki, K.; Nomura, K.; Yoshii, E. J. Chem. Soc., Chem. Commun. 1989, 354.

8. Kraus, G. A.; Li, J.; Gordon, M.S.; Jensen, J. H. J. Org. Chem. 1995, 60, 1154.

9. Giles, R. G. F.; Green, I. R.; Oosthuizen, F. J.; Taylor, C.P. Tetrahedron Lett. 2001, 42, 5753.

10. Kobayashi, K.; Uchida, M.; Uneda, T.; Tanmatsu, M.; Morikawa, O.; Konishi, H. Tetrahedron Lett. 1998, 39, 7725.

11. Nguyen Van, T.; Kesteleyn, B.; De Kimpe, N. Tetrahedron 2001, 57, 4213.

12. Giles, R.G. F.; Green, I. R.;V.I. Hugo, P.R.K. Mitchell and S.C. Yorke, J. Chem. Soc., Perkin Trans. 1 1983, 2309.

13. Chorn, T. A.; Giles, R. G. F.; Green, I. R.; Mitchell, P. R. K. J. Chem. Soc., Perkin Trans. 1 1983, 1249.

14. Cameron, D. W.; Cromartie, R. I. T.; Kingston, D. G. I.; Todd, A. R. J. Chem. Soc. 1964, 51.

15. Cameron, D. W.; Chan, H. W.-S.; Thoseby, M. R. J. Chem. Soc. (C) 1969, 631. 16) A preliminary account of some of this work has been reported previously.

16. Giles, R. G. F.; Green, I. R.; Taylor, C. P. Tetrahedron Lett. 1999, 40, 4871.

17. Trost, B. M. Tetrahedron 1977, 33, 2615.

18. Semmelhack, M. F.; Bozell, J. J.; Keller, L.; Sato, T.; Spiess, E. J.; Wulf, W.; Zask, Tetrahedron 1985, 41, 5803.

19. Semmelhack, M. F.; Kim, C.; Zhang. N.; Bodurow, C.: Sanner, M.; Dobler, W.; Meier, M. Pure and Appl. Chem. 1990, 62, 2035. 
20. Giles, R. G. F.; Lee Son, V. R.; Sargent, M. V. Aust. J. Chem. 1990, 43, 777.

21. Giles, R. G. F.; Green, I. R.; Knight, L. S.; Lee Son, V. R.; Yorke, S. C. J. Chem. Soc., Perkin Trans., 1 1994, 859.

22. Snyder, C. D.; Rapoport, H. J. Am. Chem. Soc. 1972, 94, 227.

23. Jacob, P.; Callery, P. S.; Shulgin, A. T.; Castagnoli, N. J. Org. Chem. 1976, 41, 3627.

24. Rosen, B. I.; and Weber, W. P. J. Org. Chem. 1977, 42, 3463. 